\title{
Coupling Performance Analysis of Three Pillars of Enterprise Management
}

\author{
Yifeng Wang', Yilong Yu ${ }^{2}$ \\ School of Economics and Management, Xidian Univ., Xi'an 710071, China
}

\begin{abstract}
The three pillars of business management are strategic management, marketing management and project management. In the actual operation of the enterprise, strategic management, marketing management and project management need to be effectively matched. This paper uses the coupling mechanism of strategy, marketing and project and "entropy" theory to build a coupling model of enterprise strategy - resource - marketing - resource - project. Applying the coupling model, we explain the method of calculating the coupling degree of each pairwise combination separately, providing the support of mathematical method for strategic project selection and marketing project management and optimal allocation of resources, making their own contribution to the development of enterprise management theory, It also has a reference value for other industries.
\end{abstract}

Keywords: strategic management, marketing management, project management, coupling model

\section{Introduction}

The concept of project management came from the Manhattan Project in the United States. With the development of information technology, the correlation between various businesses in an enterprise is getting higher and higher. The boundary of a traditional enterprise is gradually blurred and the business activities of an enterprise are increasingly project-centered. However, in the survey and research, we found that the implementation of project management was not satisfactory and the failure rate of the project ranged from $80 \%$ to $90 \%$. The reason for the failure is that many enterprises carry out projects that are not related to the organizational development strategy. Most enterprises tend to focus on the application of certain marketing elements and marketing tools in marketing activities. However, on the whole marketing process lacks an overall perspective of a project macro analysis, planning and control.

Enterprise project management and marketing management should serve the enterprise strategy. The implementation of enterprise strategy relies on scientific and rational project management and marketing management. The implementation of enterprise marketing project management in the scenario of strategic project management is the key to the long-term development of contemporary enterprises.

The strategic management, marketing management and project management are combined to form a systematic, standardized and modular theory of enterprise management that uses the three pillars as the core, the match between the two elements and the application of the single factor as the extension. Establish a relationship model that includes strategy, project and marketing, enrich the theoretical foundation of business management and the knowledge system of project management, and provide theoretical guidance for more effective management of the enterprise.

In the contemporary business environment, the key to the long-term development of an enterprise lies in innovation and projects. As a one-time activity, it plays an important and innovative role in the enterprise. In practice, enterprises should not only operate repetitive business in the traditional way, but also support and manage a large number of new projects, facing the coordination between operation management and project management. At the same time, both day-to-day operations and project management should serve the strategy. The realization of the enterprise strategy relies on scientific and rational operation and project management. International project management ideas and methods have been more and more enterprises applied to business management practices, but in China there is still a lack of systematic research in this area, enterprises are also in urgent need of theoretical guidance in this regard. Projects, Routine Operations and Organizational Strategy and Mission Integrated management issues have had many adverse effects and significant economic costs for the economic development and operation of our country.

Strategic management theory and project management theory so far, has formed a relatively mature theoretical system. Project management theory is a new field of management science, which differs greatly from the general management of the enterprise. With the development of the enterprise, a relatively complete system of disciplines is gradually formed. The Project Management Institute PMI defines a project as a project that refers to all one-time, noncontinuous work or project in an organization that combines human and other resources into a single, short-term organization for a specific purpose. For the first time, Roland Garis (2015) put forward the idea of "implementing business strategy by project" at the 1990 International Project Management Conference in Vienna, opening the way for strategic and project relations research. Ge Baoshan (2012)think "strategic management and project management must be organically combined, from the enterprise development strategy to start the introduction of project management decision-making, can effectively promote the implementation of corporate strategy." Shi Xueyong (2013) and other think "strategic management also lacks effective methods and tools to ensure the implementation of the strategy," "remove those projects that are not related to the strategic objectives and avoid the diversion of corporate resources." Bredillet (2014) aimed at enterprise project management can help solve the problem of enterprise

\section{Volume 6 Issue 12, December 2017}




\section{International Journal of Science and Research (IJSR) \\ ISSN (Online): 2319-7064}

Index Copernicus Value (2016): 79.57 | Impact Factor (2015): 6.391

functional management difficult to achieve strategic management of enterprises, building a "business strategy project management - internal and external environment," a combination of models. Zeng Yucheng (2015) think "enterprise project management if not based on the enterprise development strategy is difficult to be successful." Qi Anbang (2010) and others argue that "an organization's strategy is not achieved through such a project as a project, and sometimes it must be supplemented by the organization's day-to-day operations." "The relationship between an organization's strategy and its daily operation is not always directly put forward, But through the project and the daily operation of the relationship reflected ". A.P. Van Der Merwe (2012) argues that the functioning and growth of a business requires a new look and study of the interplay of strategy, organizational structure, processes and projects. Dai Shufen (2011) and other think "how to coordinate business strategy, project, operation of the relationship between the three, from a higher point of comprehensive management, has important research value."

\section{Theoretical Framework}

In physics, coupling refers to the phenomenon in which two (or more than two) systems or forms of motion interact with each other through various interactions. When the system or between the internal elements of the system properly with each other, promote each other as a benign coupling; the other hand, as an undesirable coupling. The degree of coupling is the degree that describes how the system or element interacts with one another. When the coupling parties are interrelated, interacting and interdependent, they form a coupling relationship between the elements. The introduction of coupling theory into the study of management, through interdisciplinary research to solve the existing problems of management, is of great significance for the development of management research paradigm. Zeng Yucheng, who believes that "the current management studies, most of the disciplines use a relatively closed research paradigm. Although the development of this discipline has played a certain positive role, but with the market and science and technology increasing changes, no matter what kind of theory to explain the problems faced by enterprises alone, has shown more and more the inherent limitations Qi Anbang (2010) pointed out in his research that "the reason why business managers lack the ideas and concepts of integrated management is that there is still no integrated theory and method of integrated management of daily operations and organizational strategies and missions." Dai Shufen (2011) that "how to coordinate business strategy, project and operation of the relationship between the three, from a higher point of comprehensive management, has important research value." Using the paradigm of coupling research, on the basis of the special laws of each independent discipline, we study the theoretical system of the coupling of related disciplines, including the concept of forming coupling, the content of coupling, the principle of coupling and the mechanism of coupling. This will not only promote the further development of all sciences, but also promote cross-integration of disciplines and broaden their fields of development through coupling. Coupling management of business strategy, marketing and project as a new theory and method has expanded the theoretical system of project management and is a major improvement and breakthrough in current business management theory

\subsection{Analysis of the Coupling Mechanism of Enterprise Strategic Management, Marketing Management and Project Management}

(1) Coupling between strategic management and project management

There is a certain relationship between strategic management and project management, and the interaction between the two is not directly, but through a medium, in other words, through some kind of intermediary variables, the output of the strategic management theory is transformed into the input of the project management theory. The same is true of the reverse transformation mechanism that translates the output of enterprise project management into strategic management input. The strategic management and project management of an enterprise are dynamic processes that interact with each other and interact with each other through mutual coupling and eventually move in the same direction.

(2) The coupling of enterprise project management and marketing management

An organization's strategy includes the survival and development of two parts, project management more for the strategic development of enterprise organizations and growth services, and marketing management is more for business survival and continuity of service. When the organizational strategy is established, companies need to divide the strategy into different projects, according to the project implementation business day-to-day operation of the marketing management. Enterprise project management and marketing management is the coupling of the marketing management of enterprises in a variety of one-time activities as a project, the project management using specialized methods and techniques to manage it, the organization level integration of marketing projects in various resources, ensure that the goals of each marketing project consistent with the marketing strategy of the enterprise, and ultimately achieve the mission of the enterprise.

(3) The coupling of enterprise strategic management, project management and marketing management

Professor Michael Porter classifies the business activities into nine basic activities such as $\mathrm{R} \& \mathrm{D}$, production and marketing. He believes that the enterprise value chain is a system composed of these interconnected activities. The links between functional activities through optimizing and coordinating can bring competitive advantage. Similarly, the three pillars of business management, strategic management, project management, marketing management, respectively, the three management has its own advantages and uniqueness, the same drawbacks. According to the philosophical principle that the overall utility is greater than the sum of simple parts, the coordination and integration of organizational strategy, project activities and marketing activities can bring competitive advantage to enterprises through the comprehensive application of various management methods in the general direction of corporate strategy. Strategic management addresses a directionality

Volume 6 Issue 12, December 2017 


\section{International Journal of Science and Research (IJSR) \\ ISSN (Online): 2319-7064}

Index Copernicus Value (2016): 79.57 | Impact Factor (2015): 6.391

problem and identifies ways to achieve long-term goals. Project and operations management address a matter of executive force, and they are strong drivers of turning business visions and goals one step at a time in the direction of the strategy into reality. Business managers should establish a three-coupling concept, to guide the production management activities.

\subsection{The characteristics of the coupling of enterprise strategic management, marketing management and project management}

Strategic. In the process of business operation, enterprises should formulate strategies according to their own project and the ability of daily operation and management and internal and external conditions, and then determine the strategic projects and specific projects of the enterprise from the strategy of the enterprises and implement these projects. At the same time, the daily operations management according to the strategy provides support for the project management and adjusts the enterprise strategy according to the performance of project management and routine operation so that the enterprise can develop in a virtuous cycle.

Dependency. In enterprise management practice, the implementation of the strategy depends on the completion of a number of independent projects, the completion of the strategic objectives depends on the degree of realization of the project objectives. At present, the production of enterprises tends to be more and more small quantities. This makes the marketing of each particular product and service uniquely specific and time-efficient. This situation has promoted the application of project management in the marketing activities of enterprises, the nature of the marketing activity determines the type of project management that the company uses. Enterprise project management and marketing management serve the overall corporate strategy. In turn, the maturity of the development of project management in turn will have varying degrees of impact on the company's strategic management and marketing management. Combining the three management methods of an enterprise can achieve symbiotic effects that are larger than their respective development.

Two-way action. Enterprise strategy can be divided into overall strategy and stratified strategy. The overall strategy of the enterprise guides the production and operation of the enterprise, and the marketing activities and project management of the enterprise must be subject to the overall strategy of the enterprise. According to different functional departments or management levels, the overall strategy of an enterprise can be decomposed into a plurality of small strategies that are interrelated and independent of each other. The strategy and project management at all levels are effectively combined, and the actual operation of the marketing management Small level strategy. Changes in corporate strategy can lead to changes in project activities and marketing activities. Conversely, adjustments in corporate marketing activities and project management based on actual conditions can also affect corporate strategy. According to the different functions of the department or the management level, and can be a number of small strategy into the overall strategy of the enterprise is interrelated and mutually independent, effective combination of strategy and project management of all aspects, the realization of small enterprise strategy at all levels in the specific operation process of marketing management. Changes in corporate strategy can lead to changes in project activities and marketing activities. Conversely, adjustments in corporate marketing activities and project management based on actual conditions can also affect corporate strategy.

\section{The formation of a coupled model of strategic management, marketing management and project management}

\subsection{The coupling elements of enterprise strategic management, marketing management and project management}

Enterprise strategic management and project management, marketing management as a interdependent symbiotic coupling system is an open system that enables each system to evolve self-organized according to its inherent laws, but also make each system form coupling in time and space. Enterprise strategic management, project management and marketing management coupled with the main elements of the strategy, resources, projects, marketing. The strategy includes the vision of the enterprise, the mission of the enterprise, the goal of the organization, etc. The resources include labor, technology, equipment, capital, raw materials, etc. The project includes the start-up, planning, implementation and completion of the project. The marketing activities include market analysis, financial control, production activities etc... Specific elements according to the actual situation of the enterprise can make specific adjustments.

\subsection{The coupling node of enterprise strategic management, marketing management and project management}

Enterprise strategic management and project management, marketing management coupled with the intermediary elements of resources. In the overall coupling process, the enterprise strategic management and project management, marketing management are subject to the overall goal of the enterprise, the ultimate goal is to maximize the value of the enterprise. At different stages of the product life cycle, there are different levels of strategic objectives, project strategies and marketing activities. The three are in the same general direction and have different combinations and degrees of coupling at different levels.

\subsection{The mode of enterprise strategic management, marketing management and project management}

The way of strategic management, project management and marketing management coupling is based on the philosophy of project management, which mainly shows as interaction, interaction and interdependence.

\section{Volume 6 Issue 12, December 2017}




\section{International Journal of Science and Research (IJSR) \\ ISSN (Online): 2319-7064}

Index Copernicus Value (2016): 79.57 | Impact Factor (2015): 6.391

(4) Enterprise Strategic Management and Project Management

The strategic objectives of the enterprise decide which project to choose and how to decide the project management. The project management must be consistent with the development direction of the entire enterprise. Project management is divided into single-project management and multi-project management. Enterprise multi-project management is an integral part of the substantive strategic management of an enterprise. It is the implementation link of substantive strategy and the link and pivot of enterprise strategic management and individual project management. The allocation of resources to project management depends on the degree of cooperation between the project and the strategy.

The practice of project activities is the evaluation and feedback on the corporate strategy. The implementation of specific projects will lead to the implementation of the organizational strategy. The outcome of the implementation of the project activity determines the extent to which the business strategy is completed and the level of efficiency achieved. When the project makes specific changes according to environmental requirements, it will correspondingly result in the adjustment of the corporate strategy.

\section{(5) Enterprise Marketing Management and Project} Management

Project definition and decision-making and design goals determine the specific implementation of marketing activities, business marketing activities must strive to recover and compensate for the project phase of the investment costs. Project planning determines the organizational structure of marketing activities, marketing strategies and management methods. The resources needed for marketing activities are allocated by the project decision of the enterprise.

Marketing activities require enterprises to accomplish their goals with limited resources and constraints. This requires that planning of enterprise projects fully take into account the constraints of manpower, material and financial resources, and achieve the goal of the enterprise at the lowest cost. Marketing activities are the concrete operation of the enterprise's production activities, facing the challenges of the internal and external environment and the limitations of their own adaptability. At this time, enterprises need to adjust their marketing activities according to the actual situation. Enterprises' project plans also need to be adjusted according to the actual situation and can not be rigidly adhered to the text plan.

(6) Enterprise project management, marketing management and strategic management

The strategic goal of the enterprise is to move forward. Marketing activities and project management are the tools and motivators for achieving the goals. Strategic objectives in the direction of the provisions of enterprises at the same time, but also rely on the enterprise project planning and marketing activities to implement the concrete implementation. The level of project management maturity is a key factor in the implementation of marketing strategy and marketing activities. The higher the maturity of project management, the better coordination with the corporate strategy, which lays the foundation for the promotion of marketing activities. Marketing management is the most basic level in production management activities of enterprises and the interface between the enterprises and the outside world. The ability of marketing activities to adapt to the external environment determines whether the enterprise goals can be achieved and the correctness of the enterprise strategy formulation and the effectiveness of project management

\section{(7) Intermediary conversion of resources}

Resources are the key elements of an enterprise's production and operation activities. Enterprise resources are the set of various factors of production that are owned, controlled or available in the process of providing products or services to the community and that can help achieve their business objectives. Enterprise resources are essential for the normal production and operation activities of enterprises, all aspects of the normal operation of enterprises are inseparable from corporate resources. The realization of enterprise strategic goals, the normal conduct of project activities, the implementation of marketing plans are inseparable from the support of resources.

The nature of resources determines the nature of all aspects of business operations. Hollis B. Chanari, a professor at Harvard University and a world economic adviser to the World Bank and a world-renowned economist, believes that economic resources flow from less productive industries to more productive industries. and thus promoting an equal marginal productivity of capital and labor among different industries. The degree of endowment of resources determines the strategy adopted by the enterprise, the specific circumstances of the project planning and the feasibility of marketing activities.

Resource consumption and regeneration. Reasonable allocation of resources is the key to the success of enterprise project management. Synchronization of enterprise information acquisition in the information age and the integration of off-site resources in the network virtual space make it possible for enterprises to integrate resources and exchange resources. Chen Ning et al. Established the mathematical model of resource allocation efficiency in the study, which provided an effective theoretical method and evaluation basis for the rational utilization of resources and the creation of heterogeneous resources.

\subsection{The coupling model of enterprise strategic management, marketing management and project management}

From the above analysis, the three systems of enterprise strategic management, project management and marketing management can be defined as the coupling strength of enterprise strategy-resource-project-resource-marketing through the interaction, interaction and interdependence of their respective coupling elements, The coupling model shown in Figure 1. 


\section{International Journal of Science and Research (IJSR) \\ ISSN (Online): 2319-7064}

Index Copernicus Value (2016): 79.57 | Impact Factor (2015): 6.391

Figure 1 shows the business strategy, project, resources, marketing, the logical relationship between. And thus can constitute different types of strategic management and project management, marketing management coupling model. For example, If the enterprise adopts the enterprise core competence strategy, the enterprise strategy and project focus on differentiating the core competence and non-core competence of the enterprise, carefully analyze each business of the company and all fields involved, and identify, cultivate and develop the core ability that is difficult to be imitated by the competitors. Focus their own resources to carry out core projects, access to competitive advantages, the completion of strategic objectives for enterprises to create good returns. Outsourcing the businesses that have little to do with their core competencies to maximize the use of internal resources.

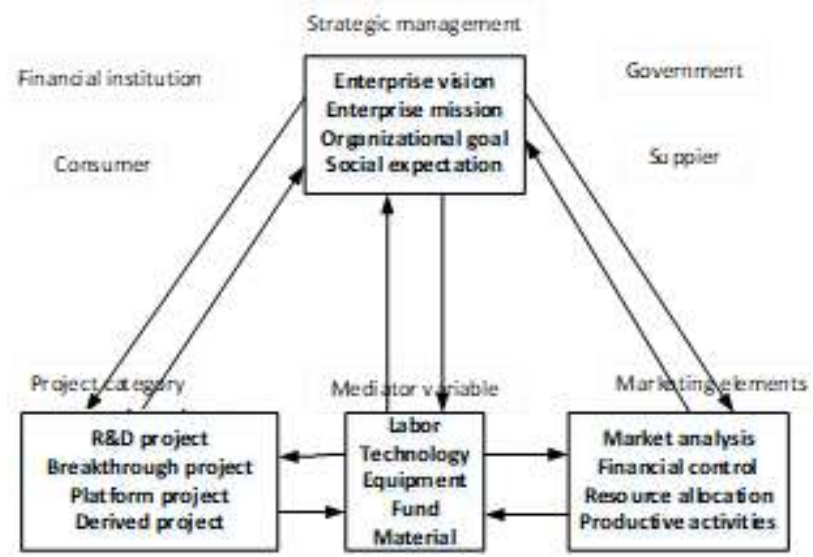

Figure 1: strategic management, project categories, marketing elements coupled model

\section{Calculation of corporate strategy, project and marketing coupling}

The so-called coupling degree refers to the interaction between two entities or systems through a medium, the degree of interaction between the value of $0 \sim 1$, reflecting the strength of the interaction between the two. In order to further reveal the enterprise strategic management and project management, marketing management and project management as well as strategic, marketing and project the interaction between the three, the interaction of deep coupling mechanism. based on the "entropy" theory of physics, this paper establishes a coupled mathematical model of enterprise strategy - resource - project - resource marketing with enterprise resources as its medium or medium, and provide a more scientific and mathematical methods for enterprises based on existing resources, strategic objectives, project options, the choice of marketing activities. The degree of coupling between business strategy and project, project and marketing refers to the intensity of the interaction between the three variables of strategy and project and marketing. The larger the coupling value is, the higher the degree of coupling between strategy and project and marketing is, and the stronger the consistency among different links in the enterprise, the greater the possibility of achieving the goal.

\subsection{The calculation of the coupling degree of enterprise} strategy and project and marketing

The concept of entropy originated in physics first, used to measure the degree of disorder of a thermodynamic system. The second law of thermodynamics, also known as "Law of Entropy," shows that the degree of total disorder in an isolated system does not diminish in nature. In information theory, entropy is used to measure the expected value of a random variable. It represents the amount of information lost during the signal transmission before it is received, also known as information entropy. In 1948, Claude Elwood Shannon introduced the entropy of thermodynamics into information theory, so it is also known as Shannon entropy. "Entropy" is a measure of system state uncertainty. When the system is in several states and the probability of each state is $P i(\mathrm{i}=1,2,3, \ldots, \mathrm{n})$, the entropy of the system is:

$$
E=-\sum_{i=1}^{n} P_{i} \log \left(2, P_{i}\right)\left(0 \leq P_{i} \leq 1\right)
$$

The "entropy" theory is applied to the field of enterprise strategy and marketing and project management, the coupling degree formula is as follows:

$$
O H=-\varepsilon \sum_{i=1}^{n} P_{i} \log \left(2, P_{i}\right)\left(0 \leq P_{i} \leq 1\right), \sum_{i=1}^{n} P_{i}=1, \varepsilon=1 / \ln n
$$

$P i$ refers to a resource on the strategy or project, the standardization of marketing satisfaction.

The definition of entropy shows that the degree of coupling must be a value between 0 and 1 . When the difference of $P i$ distribution is bigger, the coupling degree is smaller, the closer it is to 0 . When the difference of $P i$ distribution is smaller, the larger the coupling degree is, the closer it is to 1 . In extreme cases, all variables $P i$ are equal, that is, when both are $1 / \mathrm{n}$, the coupling degree equals $1(\mathrm{E}=1)$. Suppose $\mathrm{Pi}$ (normalized value) is the resource's normalized satisfaction rate for a strategy (or project, marketing). Coupling degree $(\mathrm{OH})$ and the relationship between the main manifestations:

If the distribution is more concentrated, that is, all $P i$ values are substantially equal, then the coupling value is higher and closer to 1 . The coupling degree is explained as follows: the rate of resource to strategy (or project and marketing) is basically equal, that is, there is no bottleneck resource or bottleneck resource, and resource balancing rate is high. By adjusting the level of enterprise strategy (or item size, range of marketing activities), The degree of coupling between the company's strategy (or project, marketing) and resources can be greatly enhanced to reach an infinitely close coupling degree of

If the distribution is more scattered, that is, the difference between $P i$ values is very large, then the coupling value is lower and closer to 0 . The coupling degree is explained as follows: Resources have very different satisfaction rates for strategies (or projects, marketing) and low resource balance rates, making it more difficult to achieve higher coupling values for firms regardless of resource strategic (or project, marketing) adjustments. 


\section{International Journal of Science and Research (IJSR) \\ ISSN (Online): 2319-7064}

Index Copernicus Value (2016): 79.57 | Impact Factor (2015): 6.391

The above idea is to establish the basic guiding ideology of enterprise strategy - resource - project - resource - marketing coupling model synthesis. Because the coupling of enterprise strategy and project and marketing is based on the existing resources of the enterprise, the organic coupling of the enterprise strategy and project and marketing must be realized in five steps: The first step is to define the business strategy, decompose the strategic target refinement index, determine the enterprise intends to plan the implementation of the project, break down the project refinement index, determine the enterprise ready to use the marketing program, and determine the project, marketing and strategic common types and classification of resources; The second step, calculate the degree of coupling of business strategy and resources; The third step, the degree of coupling between enterprise projects and resources; The fourth step, corporate marketing and resource coupling degree; The fifth step is to find out the coupling degree of strategy, marketing and project through the coupling degree of strategy and resource, the coupling degree between project and resource and the coupling degree between marketing and resource.

\subsection{Determine the decomposition strategy, project type, marketing plan, resource type}

Assume that the strategy $\mathrm{A}$ is formulated by the enterprise, there are $\mathrm{n}$ sub-strategic objectives, $\mathrm{n}$ alternative projects, $\mathrm{n}$ marketing plans, and $\mathrm{x}$ resources for achieving strategic, marketing and project goals.

\subsection{The Coupling Degree Model of Enterprise Strategy and Enterprise Existing Resources}

To establish a coupling degree model between strategy and resources, we first make the following assumptions:

1) Suppose the $\mathrm{j}$-th $(1 \leq \mathrm{j} \leq \mathrm{x})$ resource satisfies the subproblem of item $\mathrm{i}$-th $(1 \leq \mathrm{i} \leq \mathrm{n})$ as follows: $t_{i j}$

2) Standardize $t_{i j}$ and set its normalized value is $p_{i j}$, so:

$$
p_{i j}=t_{i j} / \sum_{j=1}^{x} t_{i j}
$$

Based on the above assumptions, the coupling degree between enterprise resource and sub-strategy $\mathrm{i}$ is as follows:

$$
\begin{aligned}
& C_{i}^{s}=\left(-\varepsilon \sum_{j=1}^{x} P_{i j} \ln P_{i j}\right) * \min _{1 \leq j \leq n}\left(t_{i j}\right) \\
& \text { s.t. }=\left\{\begin{array}{l}
\sum_{j=1}^{x} P_{i j}=1 \\
0 \leq t_{i j} \leq 1,0 \leq P_{i j} \leq 1 \\
p_{i j}=t_{i j} / \sum_{j=1}^{x} t_{i j} \\
1 \leq i \leq m, 1 \leq j \leq x,
\end{array}\right. \\
& \text { ve model we can see: } 0 \leq C_{i}^{s} \leq 1
\end{aligned}
$$

From the above model we can see: $0 \leq C_{i}^{s} \leq 1$

$C_{i}^{s}=0$ means that none of the $\mathrm{x}$ kinds of resources has any one of the resources. Therefore, the degree of coupling between the $\mathrm{i}$-th $(1 \leq \mathrm{i} \leq \mathrm{m})$ strategy and the resources is zero. In other words, the $\mathrm{i}$-th $(1 \leq \mathrm{i} \leq \mathrm{m})$ strategy is unlikely to be realized. This is a rare occurrence that occurs when a business has no idle capital to buy a bottleneck resource, and at the same time, a company has no such resource at all.

$C_{i}^{s}=1$ refers to the enterprise's resources to meet the strategic level of $1 . C_{i}^{s}=1$ happened, indicating that business resources are sufficient, fully able to achieve the existing strategic objectives, in other words, the strategic objectives set by the enterprise is low, it is difficult to effectively mobilize the enthusiasm of staff, the enterprise is very conservative. At this point, enterprises should appropriately raise their strategic objectives, control the size of the risks in strategic planning, mobilize the enthusiasm of staff innovation, and inject vitality into the development of the enterprise.

The overall coupling of strategy and resources is defined as:

$$
C^{s}=\sqrt{\frac{\sum_{i=1}^{n}\left(C_{i}^{s}\right)^{2}}{n}}
$$

\subsection{The Coupling Degree Model Between Marketing Activities and Enterprise 's Existing Resources}

To establish a coupling degree model between marketing activities and resources, the following assumptions are made first:

1) Suppose the $j$-th $(1 \leq j \leq x)$ resource satisfies the $i-t h(1 \leq i \leq n)$ marketing plan as: $t_{i j}$

2) Standardize $t_{i j}$ and set its normalized value is $p_{i j}$, so:

$$
p_{i j}=t_{i j} / \sum_{j=1}^{x} t_{i j}
$$

Based on the above assumptions, the coupling model of enterprise resource with the $\mathrm{i}$-th marketing scheme is as follows:

$$
\begin{gathered}
C_{i}^{p}=\left(-\varepsilon \sum_{j=1}^{x} P_{i j} \ln P_{i j}\right) * \min _{1 \leq j \leq n}\left(t_{i j}\right) \\
\text { s.t. }=\left\{\begin{array}{l}
\sum_{j=1}^{x} P_{i \ddot{j}}=1 \\
0 \leq t_{\ddot{j}} \leq 1,0 \leq P_{i \ddot{j}} \leq 1 \\
p_{i j}=t_{i j} / \sum_{j-1}^{x} t_{\ddot{j}} \\
1 \leq i \leq m, 1 \leq j \leq x,
\end{array}\right.
\end{gathered}
$$

From the above model we can see: $0 \leq C_{i}^{p} \leq 1$

Similarly, the overall coupling between marketing programs and resources is defined as:

$$
C^{p}=\sqrt{\frac{\sum_{i=1}^{n}\left(C_{i}^{p}\right)^{2}}{n}}
$$

\section{Volume 6 Issue 12, December 2017}


4.5 The Coupling Degree Model between Enterprise Project and Enterprise Existing Resource

To establish a coupling degree model between project and resource, the following assumptions should be made:

1) Suppose the $j$-th $(1 \leq j \leq x)$ resource satisfies the $i-$ th $(1 \leq i \leq n)$ project as: $t_{i j}$

2) Standardize $t_{i j}$ and set its normalized value is $p_{i j}$, so:

$$
p_{i j}=t_{i j} / \sum_{j=1}^{x} t_{i j}
$$

Based on the above assumptions, the coupling model of enterprise resource with the $\mathrm{i}$-th project is as follows:

$$
\begin{aligned}
C_{i}^{y}=\left(-\varepsilon \sum_{j=1}^{x} P_{i j} \ln P_{i j}\right) * \min _{1 \leq j \leq n}\left(t_{i j}\right) \\
\text { s.t. }=\left\{\begin{array}{l}
\sum_{j=1}^{x} P_{\ddot{j}}=1 \\
0 \leq t_{\ddot{j}} \leq 1,0 \leq P_{\ddot{j}} \leq 1 \\
p_{\ddot{j}}=t_{i j} / \sum_{j-1}^{x} t_{\ddot{j}} \\
1 \leq i \leq m, 1 \leq j \leq x,
\end{array}\right.
\end{aligned}
$$

From the above model we can see: $0 \leq C_{i}^{y} \leq 1$

Similarly, the overall coupling between projects and resources is defined as:

$$
C^{y}=\sqrt{\frac{\sum_{i=1}^{n}\left(C_{i}^{y}\right)^{2}}{n}}(14)
$$

\subsection{The coupling model of strategy management, marketing management and project management}

The coupling degree of strategy, marketing and project is called $C^{T}$ is weighted from the weighted average of the three parts: the coupling between strategy and resources namely $C^{s}$, the coupling between marketing and resources namely $C^{p}$, and the coupling between projects and resources namely $C^{y}$. and the final result is:

$$
C^{T}=\frac{C_{x+n+y}^{3} * C^{s} * C^{p} * C^{y}}{3}
$$

This formula shows that resources play a role of filtering and adjusting again in the process of coupling strategy, marketing and project goals if resources are sufficient to achieve strategic goals and different project types and marketing scenarios. this shows that the strategic goal of the enterprise can be realized through reasonable project planning and marketing strategy, namely, the coupling degree of the three is 1 , meanwhile the utilization rate of resources in the enterprise is relatively low, the manager's decision is more conservative, and the stable operation mode is selected.

\section{Discussion}

The famous North American psychologist and behavioral scientist Victor Vroom published his Work and Incentives in 1964, in which the famous Theory of Expectations Theory is also called "the potency-means-expectancy theory". Is a theory of management psychology and behavioral science. The theory can be formulated as: Exciting power $=$ expected value * potency. In this formula, the motivating force refers to mobilizing the enthusiasm of the individual and stimulating the intensity of the internal potential; the expectation is based on the individual's experience to determine the degree of achievement of the goal; and the valence is the value of the attainable goal to meet the individual's needs. The formula for this theory shows that the magnitude of the person's motivation to be mobilized depends on the product of the expectation and the potency. In other words, a person's grasp of the goal is greater, the higher the probability of reaching the goal, the stronger the motivation, the greater the enthusiasm. In the leadership and management work, the use of expectations theory to mobilize the enthusiasm of subordinates is of some significance.

Therefore, managers should adjust their strategic goals and marketing programs as appropriate, make new project plans, and use the multiplier effect of expectation theory to stimulate employees' enthusiasm for work and enhance their vitality.

The coupling of strategy, marketing and project $C^{T}$ is of great significance to the management of enterprises. By evaluating the degree of coupling between corporate strategy and marketing, the consistency between the marketing plan and the overall corporate strategy can be effectively maintained, the resources allocated rationally and the completion of strategic objectives ensured. By assessing the degree of coupling between the company's strategy and the project, the employees of the enterprise can make their employees understand the long-term development direction of the enterprise in depth and formulate the project plans of each stage and each part under the overall command of the enterprise strategy so as to effectively allocate resources and achieve the corporate goals. By assessing the degree of coupling between enterprise projects and marketing, the theoretical planning of enterprises can be brought into line with the actual changes of the environment, the enterprises can be placed in the real market to adjust the plans and realtime projects, guide the marketing programs and enhance the adaptability of enterprises to the environment.

This article gives a basic explanation of $C^{T}$ :

1) $0 \leq C^{T} \leq 0.35$, Very low coupling. When the degree of coupling of enterprises in this range, indicating that the strategic goals of enterprises too high, or the project needs too much resources, marketing programs are too complicated, or for three reasons. The shortage of enterprise resources, can not support the strategic objectives of enterprises, marketing activities and project

\section{Volume 6 Issue 12, December 2017}




\section{International Journal of Science and Research (IJSR) \\ ISSN (Online): 2319-7064}

Index Copernicus Value (2016): 79.57 | Impact Factor (2015): 6.391

operations, and ultimately lead to the failure of the overall planning of enterprises. Enterprises should be based on the actual situation of the strategic objectives of enterprises to ensure the reachability of business goals. Control the scope of project planning and the resources required to plan projects based on existing enterprise resources. On the basis of ensuring the strategic goals and feasibility of the project plan, the marketing plan of the enterprise should be carefully formulated so as to avoid serious derailment from the actual situation.

2) $0.35 \leq C^{T} \leq 0.65$, Low coupling. In this section, the enterprise strategy, projects and marketing activities need to be adjusted, but enterprises can also enhance the coupling between the three pillars of resources and business management through resource acquisition. Through internal resources regeneration and external resources to learn rich resources of enterprises, the strategic objectives of the enterprise fine-tuning, project planning based on the availability of resources based on the marketing program design, to ensure the success rate of production and operation of enterprises.

3) $0.65 \leq C^{T} \leq 0.82$, General coupling. The level of endowment of enterprise resources can not exactly match the resources needed for strategic goals, project planning and marketing activities. Enterprises should actively obtain bottleneck resources, improve the enterprise's resource endowment, at the same time, reduce the enterprise's development expectation at the present stage and achieve the balance of resources and strategy, marketing and projects.

4) $0.82 \leq C^{T} \leq 0.95$, Better Coupling. Within this range, the corporate strategic objectives are in line with the level of corporate resources ownership. Project planning and marketing programs designed to take full account of the internal and external environment within the constraints made in line with the direction of long-term development of enterprises. Enterprises can not stand still, even if the degree of business coupling, companies should always keep in mind the concept of theory, to enhance the strategic height of the enterprise. Innovate the management of enterprises, improve resource utilization and marketing methods, and use modern information technology to innovate enterprise project management. In the process of continuous improvement, through low-cost and differentiated, expanding the profit margins of enterprises

5) $0.95 \leq C^{T} \leq 1$, Fully coupled. The resources of the enterprise can supply the strategic development of the enterprise, the implementation of the project is unimpeded and the marketing activities have sufficient resources support. Enterprises in a stable state of development. On the other hand, it reflects the lack of adventurous spirit of enterprises, not seeking a higher development platform, low enthusiasm of staff, and loss of vitality of enterprise development. Short-term interests have blinded the eyes of managers, and their long-term development is worrying. Enterprises should be proactive, pioneering and innovative, to promote enterprises to enter the new journey of development, training managers to cultivate a sense of innovation, to develop a higher strategic goal, at the same time with a reasonable project planning and marketing programs to achieve long-term development of enterprises.

\section{Conclusion and Prospect}

This article integrates the strategic management, project management and marketing management of the three major areas, focusing on the strategic management of enterprises, project management and marketing management of the coupling degree were studied. The coupling system of strategic management, project management and marketing management is constructed. The concept of coupling, the characteristics of coupling, the coupling node, the coupling method, the coupling model and the calculation of coupling degree are stated in this paper. The second is the application of "entropy" theory to construct the coupling degree calculation model of enterprise strategy - resource - project resource - marketing, which provides the support of mathematical method for strategic project planning and marketing activities, and the data prove that the enterprise can make the resources be rationally allocated only when the three major management are fully coupled.

The development of an organization to a certain period of time must be based on the organization's daily marketing and project management capabilities and internal and external conditions to determine their strategic objectives. Then you need to determine your organization's survival and development strategy based on your organization's overall strategic goals. Then according to the organization's strategy to determine the organization's decomposition strategy and specific projects and the implementation of these projects. To further realize the strategic objectives of the organization according to the daily operation ability and the original daily operation ability realized by the implementation of the strategic project of the organization. Eventually, the strategic planning of the organization is revised according to the performance of the marketing campaign and the project, thus forming a cycle of the organizational life cycle. If this kind of lifecycle cycle of any one organization can realize this step-by-step integrated management well, the management of the organization will form a complete life cycle and can be cyclically circulated, so achieve the fundamental goal of sustainable management and continuous development of the organization.

The author's research is only a shallow attempt, yet to be more in-depth study. Scholars can combine the maturity of project management with the three pillars of business management coupling analysis. As people make further research on strategy and project, strategy and marketing, marketing and project, and the combination of the three, I believe there will be more experts and scholars involved in this aspect of research. This is also the future development trend of business management.

\section{References}

[1] Cheng Yu et al. Business model, operational effect and firm performance: Empirical study of the effectiveness 
of production technology innovation and operation method innovation $[\mathrm{J}]$. China Industrial Economics,2012,(7):83-95.

[2] Sándor Soós. Age-sensitive bibliographic coupling reflecting the history of science: The case of the Species Problem [J]. Scientometrics,2014,(1):23-51.

[3] Jun-Ping Qiu, Ke Dong et al. Comparative study on structure and correlation among author co-occurrence networks in bibliometrics [J]. Scientometrics,2014,(2):1345-1360.

[4] Zhao Dangzhi, Strotmann A. Evolution of research activities and intellectual influences in information science1996-2005: Introducing author bibliographiccoupling analysis $[\mathrm{J}]$. Journal of the American Society for Information Science and Technology, 2008,(13):2070-2086.

[5] Visualization research on author citation coupling [J]. Library and information service,2012,(12):81-84.

[6] Bornemann M. Performance implications of the business model and the moderating effects of the environment [P]. Academy of Management Annual Meeting Proceedings, 2011.

[7] Zhu Jiangli, Li Zilian. Research on the Coupling Coordination Development between Industry, Population and Space in the Yangtze River Delta Urban Agglomeration $[\mathrm{J}]$. China Population, Resources and Environment, 2015,(2):75-82.

[8] Lu Jin, Zhou Huimin. An empirical analysis of the Coupling Relationship between China provincial human capital and economic growth $[\mathrm{J}]$. quantitative and technical economics, 2013,(9).3-19

[9] Huang Muyi. Temporal and spatial characteristics of city and social economy coordinated development degree between analysis -- Taking Anhui Province as an example [J]. economic geography, 2012, (2).15-18.

[10]Liu Weiwei, Sun Ru. The high-end equipment manufacturing industry enterprise knowledge innovation and technology innovation coupling measurement study of $[\mathrm{J}]$. science and technology management, 2014,35 (7):16-22.

\section{Author Profile}

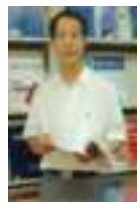

YifengWang(1964--), male, Shanxi Xi'an, professor, School of Economics and Managenent, Xidian University. Research interests: Marketing management.

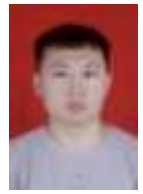

Yilong Yu (1994--), male, ShanxiDatong, master, School of Economics and Managenent, Xidian University. Major: Business management. 